\title{
The Wells, Subterranean Passage, Tunnels and Water Systems of Hagia Sophia in Istanbul
}

\author{
Çiğdem Özkan-Aygün
}

Summary

In November 2005, a survey was begun of the wells in and around Hagia Sophia Church in Istanbul. The long-term goal of the survey is the understanding of the function of the tunnels and the water systems used for Hagia Sophia and its surroundings during the Byzantine and the Ottoman periods. Alternate research methods, such as geophysical research, will be used in future surveys. The 2005 survey examined the channels that run from under the narthex and continue northwards and the southwards of the building as well as channels that run towards the atrium, hippodrome, and garden in the north. The survey resulted in the first photos of the well-bottoms in the history of Hagia Sophia.

Introduction

Generally publications on the Hagia Sophia have been concerned with such topics as architecture, mosaics, capitals, restoration and conservation, liturgy, etc. The sub-structure of the complex has not been examined in detail, although there are many legends of large subterranean cistern and secret tunnels. ${ }^{1}$ A survey of the underground area was begun in 1937 but ended prematurely because of the start of World War II. ${ }^{2}$ In 2005, the survey was re-initiated with the aim of a complete investigation of the channels, passages and wells in order to answer the questions concerning construction, purpose, and historical background as well as investigating possible connections with the channels and cisterns as well as considering the possible connections with the water system lying outside of the Hagia Sophia complex.

\section{Research Methods}

Because the wells, tunnels, and cistern often are filled with water, they must be explored with either diving equipment or with robot cameras and Ground Penetrating Radar (GPR) where access is limited. Some of the wells are filled with approximately 11 meters of water. The survey implemented the documentation of the wells and passages with photographic equipment, including underwater video cameras, thus, allowing a photographic record to be kept for the duration of the study.

The Vaulted Passage and Tunnels

There are 5 entrances to the subterranean passage. It runs through the inner narthex on a north to south axis and is constructed from a double line of vaults supported on 23 brick pillars. The pillars, on the northern side, filled in with bricks

\footnotetext{
${ }^{1}$ A. Akgündüz - S. Öztürk - Y. Baş, Üç devirde bir mabed Ayasofya, Osmanlı Araştırmaları Vakfı, 2005 .

${ }^{2}$ W. Emerson - R. L. van Nice, Hagia Sophia, Istanbul: Preliminary Report of a Recent Examination of the Structure, American Journal of Archaeology, 1943, Vol. 47, No. 4, 403-436.
} 
at a later date, measure $60 \times 60 \mathrm{~cm}$ (fig. 1). The height of the vaults is $1.4 \mathrm{~m}$ at the highest point of the arch. The floor, walls and pillars are covered with a thin layer of mortar and are painted a yellowish color. It is possible to see the watermark on the mortar layer and Erdem Yücel, the former director of the Hagia Sophia Museum, informed the team that when the vaulted passage became filled with water it had to be emptied with pumps and the drains cleaned.

The vaulted passage connects with narrower tunnels (fig. 2) from the north and south, which, at places, have heights of $50 \mathrm{~cm}$. Another tunnel branch turns towards the west and then runs parallel to the outer narthex. At the northern end of that tunnel, there is visible a water pipe that seems to head towards the atrium but it is blocked with a wall (fig. 3). Two additional branches go towards the marble urns transferred from Bergama in the Ottoman period. Water overflow from the marble urns is drained away by small channels into a subterranean tunnel via a small hole at the base of each urn. There also is a possible connection of that branch of the tunnel with the well that is closest to the urn at the southwest of the building. Initially, the tunnels may have been built to allow the escape of moisture, thus avoiding an increase of humidity, and to provide ventilation as the architect Mimar Sinan applied similar technology in 16th century mosques. As a result, since some tunnels have been blocked up, humidity has become a problem in the building.

\section{The Wells}

The project has identified nine wells from the Byzantine and Ottoman periods inside the building and the gardens of the Hagia Sophia, five of which still hold water. Two of the wells in the building were explored with underwater diving methods. The first well surveyed was situated at the northwest of the nave and was discussed initially by Grelot, and the second well opens into the grand cistern under Hagia Sophia (fig. 4). ${ }^{3}$

The depth of the well is $11.6 \mathrm{~m}$ and it is believed that the well holds an average of $10 \mathrm{~m}$ of water during the year, and aside from slight rises after rainy periods, the height of the water remains fairly stable depending on the seasons. The 2005 water level of the first well was $1.9 \mathrm{~m}$ below the floor level in November and $1.55 \mathrm{~m}$ below the floor lever in December. In comparison, the water levels measured by Antoniades in October 1904 and by van Nice in April 1940 were $1.8 \mathrm{~m}$ and $1.4 \mathrm{~m}$ below the floor level respectively. ${ }^{4}$

Despite the almost 100 years gap, the difference between the 2005 November measurement and the 1904 measurement is only $0.1 \mathrm{~m}$. The survey recorded a metal WWI canteen, a glass flask, and the remains of a glass lamp in the mud (fig. 5). The true depth of the well (to the base of the mud) will be measured by geophysical methods. The walls of the well, from the well mouth to $2.38 \mathrm{~m}$ below the floor, are constructed of irregular pieces of brick and marble joined with mortar. The remaining length of the well-shaft was dug from the bedrock on which Hagia Sophia stands. As a result, the walls are covered in rock dust, which creates low visibility for diving, thus, suggesting that the water from the well may not have been used for human consumption.

The second explored well is located in the southwest of the building close to the Ottoman marble urn. The depth of the well from the well-mouth to the bottom is

\footnotetext{
${ }^{3}$ J. W. Grelot, A Late Voyage to Constantinople, translated by J. Philips, 1683.

${ }^{4}$ W. Emerson - R. L. van Nice, Hagia Sophia, Istanbul: Preliminary Report of a Recent Examination of the Structure, American Journal of Archaeology, 1943, Vol. 47, No. 4, 409.
} 
$8.8 \mathrm{~m}$ with a water level of $6.5 \mathrm{~m}$. It is paved with travertine stones that are cut to fit the shape of the well (fig. 6) and, thus, the water is very clear because of the smooth and clean surface.

The rock and water samples were taken from the two wells. The geophysical analysis of the rock demonstrates that the wells were carved from Grovac from the Thracian formation and formed 300 million years ago during the Palaeozoic Period. The rock is very hard and, while it is not porous, water will flow through the cracks in the rock. Electrical conductivity analyses examining the dissolved materials were performed on the water samples from the two wells and suggested a similar chemical and mineral composition of the samples. The results of the well samples when compared to tap water around Hagia Sophia signal a significant difference in electrical conductivity which suggests that there is neither a connection with tap water nor is there a direct connection with rain water. Thus, the tunnels must be fed through ground water. Chloride analysis on the same sample group gave the same results.

Photographs (fig. 1, 2, 3, 5 and 6) by Engin Aygün

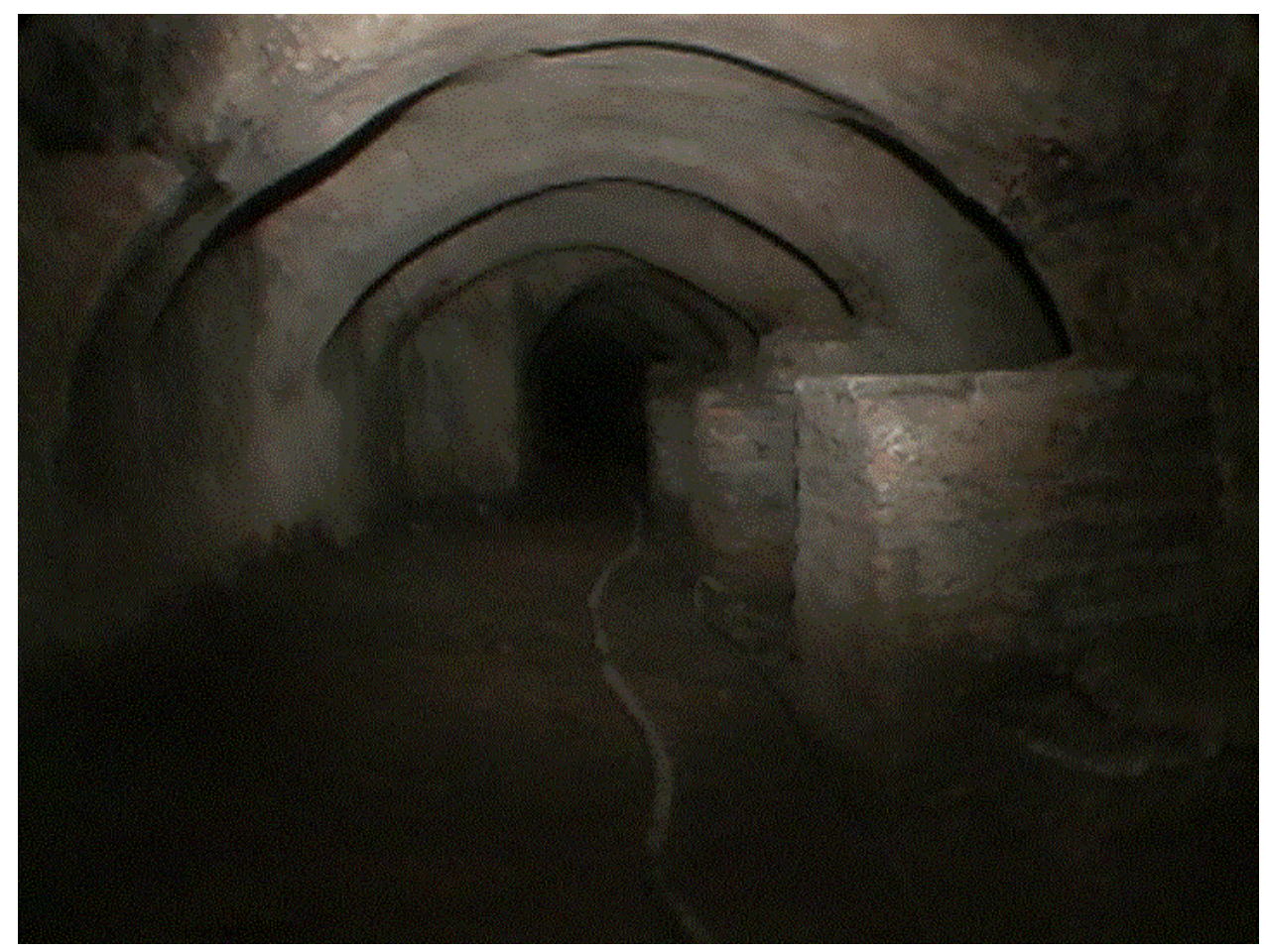

Fig. 1. The vaulted passage under the inner narthex 
Frankfurter elektronische Rundschau zur Altertumskunde 1 (2006)

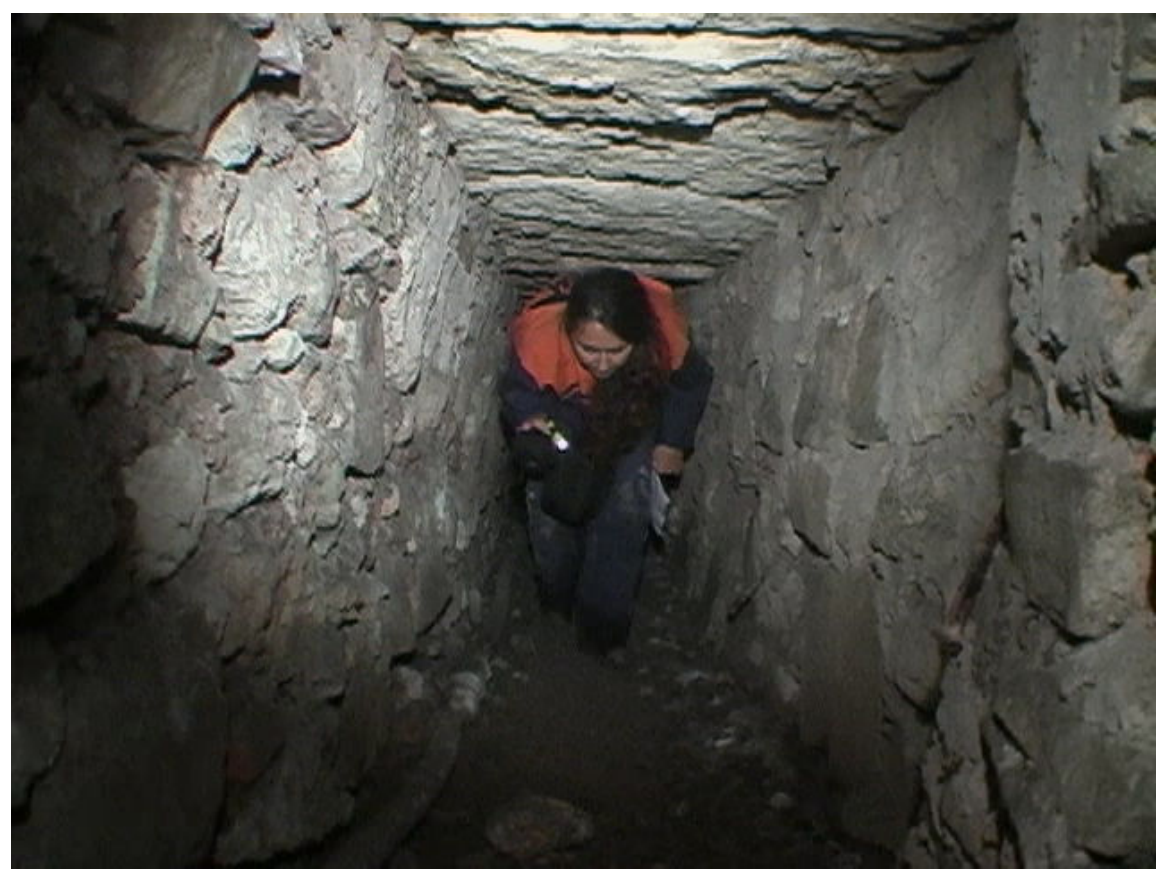

Fig. 2. The tunnels connected to the vaulted passage

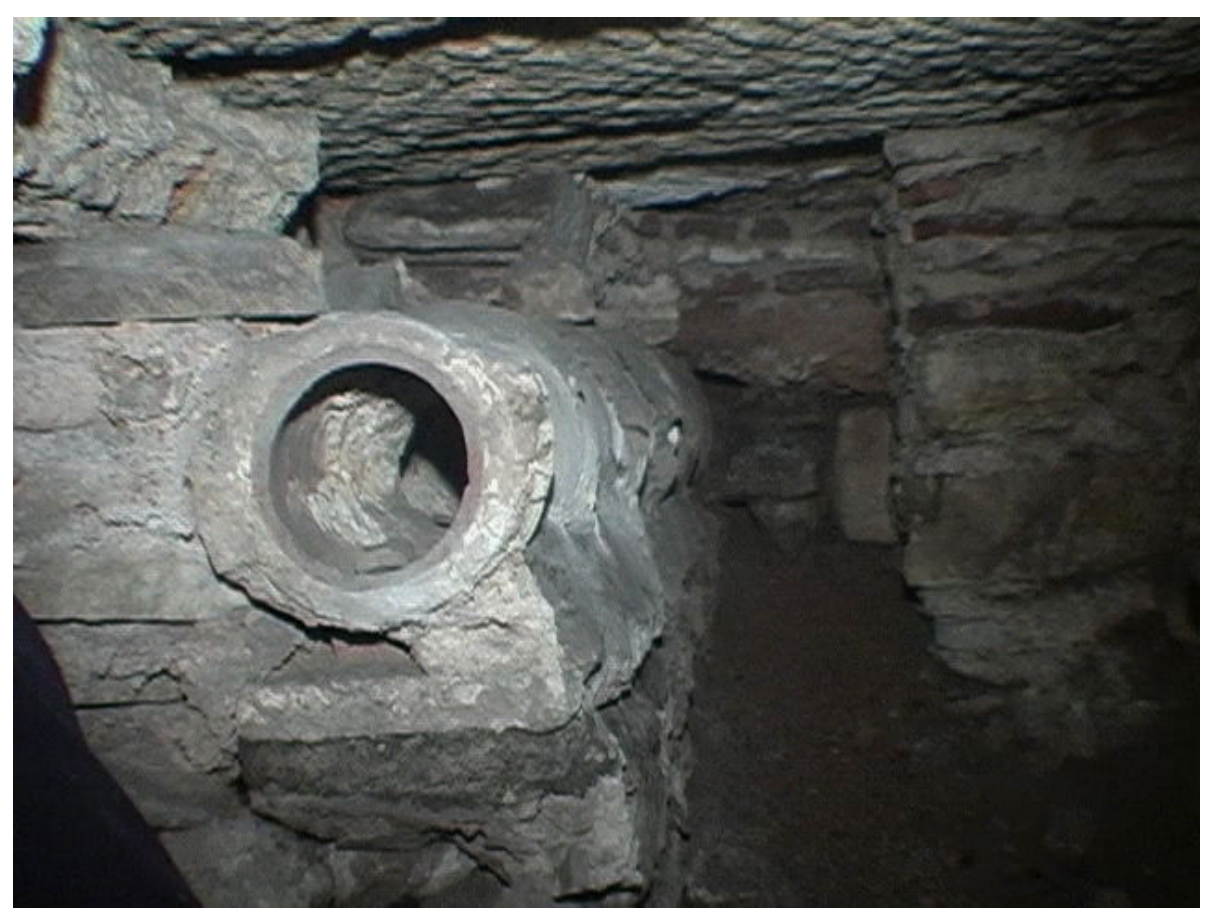

Fig. 3. The water pipe that seems to head towards the atrium 
Frankfurter elektronische Rundschau zur Altertumskunde 1 (2006)

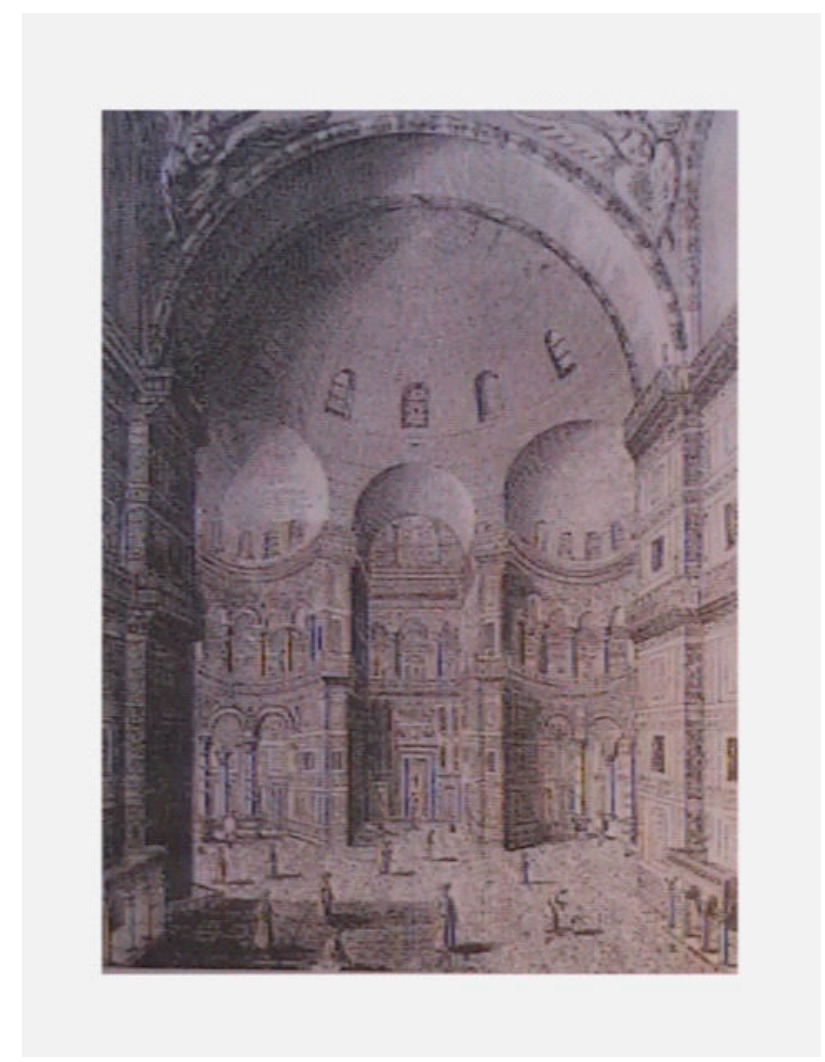

Fig. 4. Grelot 1683, Ottoman pulling water from the well no.1

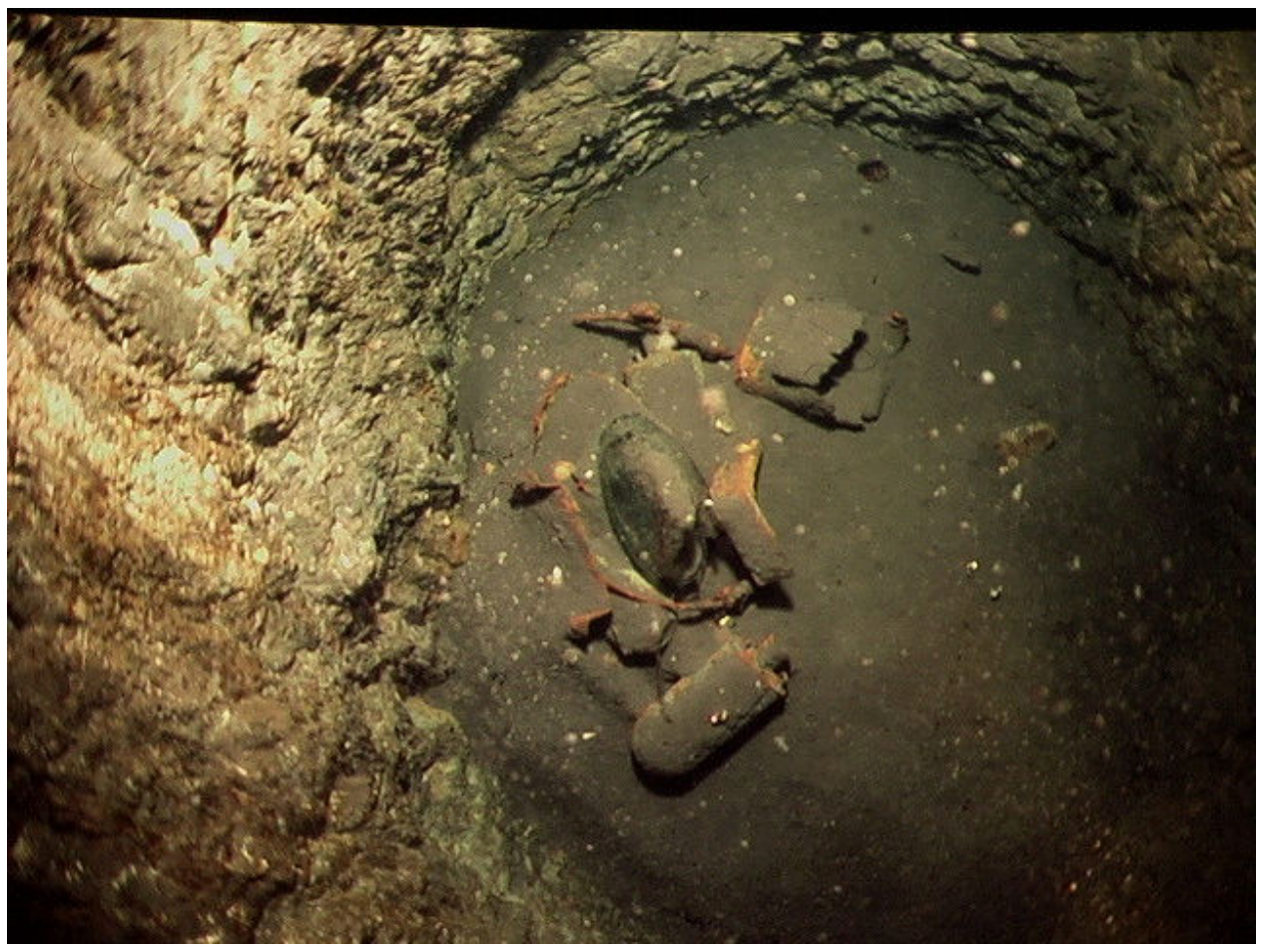

Fig. 5. The metal canteens and glass flask from the well which was filled with $10 \mathrm{~m}$ of water on the north west of the nave 
Frankfurter elektronische Rundschau zur Altertumskunde 1 (2006)

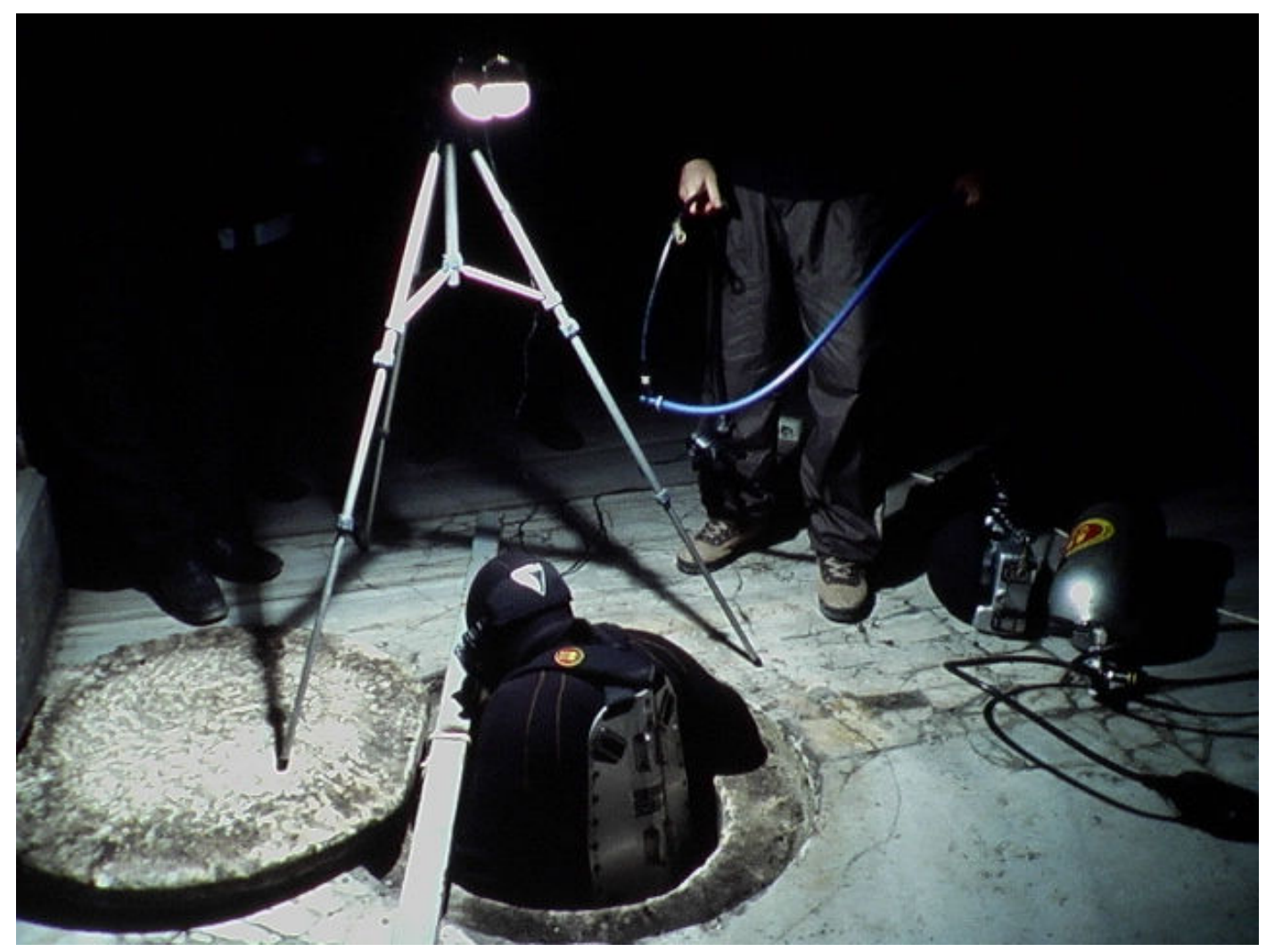

Fig. 6. The hookah system to dive in the well on the southwest of the nave 